\title{
Genetic Polymorphism among Species belong to Amaranthaceae Collected from Baghdad Province-Iraq by using RAPD -PCR
}

\author{
Mohammed Mahdi Jawad* \\ College of education for Pure Science / Ibn Al-Haitham / University of Baghdad, Bagahdad -Iraq \\ (email: dafai66@yahoo.com)
}

\begin{abstract}
Plymorphism was detected by using RAPD-PCR method in a systematic study aimed to reveal the genetic relationships among 6 collected species belonging to 4 genera of Amaranthaceae family collected from Baghdad province, which are Amaranthus retroflexus L.,A. spinosus L.,A. albus L. Alternanthera sessilis ( $L$.) R.Br. ex DC. and Gomphrena globosa L. Iresine herbstii Hook.ex Lindl.

DNA of fresh leaves was extracted using modified protocol of CTAB,six chosen random primers were used for amplifying the DNA bands.

All primers were showed polymorphism in the RAPD gel profile. 195 bands were produced with many polymorphic bands, the results arise two main groups, the first one which separated at the similarity value of (0.54) included Amaranthus retroflexus and A. spinosus, while the second group included the other Amaranthus species and contained two subgroups, the first subgroup included A. albus, and the second subgroup that appeared related correlation at similarity range of (0.41) contained 2 species; Alternathera sessiles and Gmphrena globosa, while the second subgroup of the second group included Iresine herbstis only, furthermore, this study considered as a first study at the molecular level revealed the differences and the similarities at the molecular level for this plant in Iraq.
\end{abstract}

Keywords: Amaranthus, RAPD-PCR, plant genetic variation, genetic polymorphism,DNA

\section{Introduction}

The Amaranthaceae family belongs to Caryophyllales order which is one of the largest plant orders with eleven developed families [1].A large number of wild plants and halophytes in the world belong to this order [2].

Most of the Amaranthaceae family plants are wild herbs, or cultivated shrubs [3].This family contains about 165 genera and 2,040 species and it is widely dispersed in temperate and tropical zone [4].Phenotypic variations of Amaranthaceae genera tend to have partly caused by many environmental factors. [5].The phylogeny studies based on morphological traits has limitation in data accuracy because of high subjectivity [6].Hence the importance of genetic studies, especially those related to genetic and evolutionary relations among plant varieties and species. The most important studies for determining the existence or absence of these relations among species and their source, provides workers in the field, plant classification and systematic with important information that denies or confirms their hypotheses and scientific observations in their taxonomic studies or diagnostic or anatomical of different types of plants. Efficient utilization of the most important plant genetic resources to use for nutrition and crop improvement requires clear systematic understanding of the most important traits [7].

Random amplified DNA polymorphic-PCR (RAPD-PCR) is one of the most important technics that are still widely used in the genetic relations studies among plants species and it can be used in the phylogeny studies and 
polymorphism detection, especially in the case of abundance of species, and the absence of documented information of the genetic sequences for the source of these types of approved sources. It can be used to survey large number of loci and to discover unambiguous genetic and taxonomic relationships among different taxa [8, 9]. Therefore, RAPD primers can distinguish the traits accessions more effectively than study only the phenotypic markers study [7].

Number of genera belonging to Amaranthaceae family were found in Iraq were Alternathera sessilis (L).R. Br.ex De C., Amaranthus albus L., Amaranthus caudatus L., Amaranthus retroflexus L., Amaranthus spinosis L., Amaranthus viridis L., Celosia argentea L., Celosia cristata L., Gompharena globosa L. and Irisene herbstii Hook. Ex Lindl [10].

Six species belonging to 4 genera of Amaranthaceae family are Amaranthus retroflexus L., A. spinosus L., A. albus L. Alternanthera sessilis (L.) R.Br. ex DC. and Gomphrena globosa L. Iresine herbstii Hook.ex Lindl,Were collected for this study.

Some liritures assumes that Amaranth family is the future food with high nutritional value and produces betalain as colorant [11], and it is a phytochemical marker for Amaranthaceae [12,13].Thus members of this family considered as medicinal plants because this colorant and widely used as antifungal, anti-malarial, and antiviral. Beside that, this colorant can be used as healthy food colorant. Many Phylogenetic studies of Amaranthaceae used to find an alternative plant that produces high level of Betalain [14].

\section{Materials \& Methods}

\subsection{Plant Sampling}

Samples were collected from orchards and nurseries as well as some agricultural areas in Baghdad - Iraq, during March - June, 2016 and were diagnosed and classified using the experts of plant taxonomy as well as the records of the classification of Arab and global sources on the Web. Six species belongs to four genera of Amaranthaceae family were collected from different regions (Table 1).

TABLE I: The list of Species under Study.

\begin{tabular}{|c|l|}
\hline No. & \multicolumn{1}{|c|}{ Scientific name } \\
\hline 1 & Amaranthus retroflexus L. \\
\hline 2 & A. spinosus L. \\
\hline 3 & A. albus L. \\
\hline 4 & Alternanthera sessilis (L.) R.Br. ex DC. \\
\hline 5 & Gomphrena globosa L. \\
\hline 6 & Iresine herbstii Hook.ex Lindl \\
\hline
\end{tabular}

\subsection{DNA Extraction:}

About 50 to $100 \mathrm{mg}$ of fresh leaves tissue homogenized in $1.5 \mathrm{ml}$ microfuge tubes using liquid nitrogen with hand tissue grinder.

Total genomic DNA was isolated using modified of cetylimethyl ammonium bromide (CTAB) method described by [15].the homogenized tissue powder was suspended in $2.5 \mathrm{ml}$ of CTAB DNA extraction buffer (for

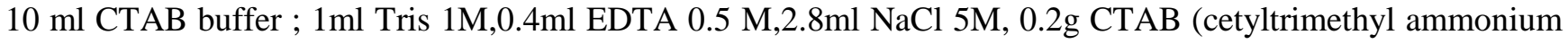
bromide),0.4g PVP(polyvinyl pyrrolidone) and $50 \mathrm{ml} \beta$-mercaptoethanol) just before use, then the suspension was mixed well, and incubated at $60^{\circ} \mathrm{C}$ for $20 \mathrm{~min}$ in order to homogenate, then followed by chloroform: isoamyl alcohol extraction (24:1), and precipitate with two volume of isopropanol at $-20^{\circ} \mathrm{C}$, then centrifuged for $5 \mathrm{~min}$ to participate the isolated DNA. The sample then washed with $1 \mathrm{ml}$ of $70 \%$ ethanol and $10 \mathrm{~m} \mathrm{M}$ of ammonium acetate. The DNA resuspended by TE buffer ( 20m M EDTA, 0.1 M Tris- HCL p H= 8), then DNA detected by $1 \%$ agarose gel electrophoresis at $100 \mathrm{~V}$ for $45 \mathrm{~min}$. then stained with ethidium bromide [16].

\subsection{PCR Technique}

Six different RAPD primers were chosen and used in this study (Table 2), which supplied by Bioneer company/Korea, master mix from the same company was used.The program of thermal cycler reaction was: 
denaturation at $95^{\circ} \mathrm{C}$ for 5 minutes, 35 cycles of $95^{\circ} \mathrm{C}$ for $30 \mathrm{sec}$, annealing at $37^{\circ} \mathrm{C}$ for 1 minute, and extension at $72^{\circ} \mathrm{C}$ for 5 minute and final extension at $72^{\circ} \mathrm{C}$ for 5 minutes.

Results were visualized on $1.5 \%$ agarose gel by using 1x TBE, 100 volts, for 2 hours, Molecular DNA ladder (100bp) was used (Bioneer).

TABLE II: The Sequences of RAPD Primers and Bands Amplification Results.

\begin{tabular}{|c|c|c|c|c|c|c|c|c|c|}
\hline Primers & $\begin{array}{c}\text { Primer sequence } \\
(5-3)\end{array}$ & NT & $\begin{array}{c}\text { Size of bands } \\
\text { (bp) }\end{array}$ & NU & $\%$ & NP & $\%$ & NM & $\%$ \\
\hline OP-A01 & CAGGCCCTTC & 11 & $120-1200$ & 3 & 27.27 & 6 & 54.54 & 2 & 18.18 \\
\hline OP-S238 & TGGTGGCGTT & 8 & $180-800$ & 2 & 25 & 5 & 62.5 & 1 & 12.5 \\
\hline OP-S147 & AGCTGCAGCC & 9 & $190-1000$ & 2 & 22.22 & 4 & 44.44 & 3 & 33.33 \\
\hline OP-S253 & GGCTGCTICC & 9 & $180-1000$ & 2 & 22.22 & 5 & 55.55 & 2 & 22.22 \\
\hline R108 & GTATTGCCCT & 10 & $180-800$ & 3 & 30 & 6 & 60 & 1 & 10 \\
\hline UBC90 & GGGGGTTAGG & 11 & $190-800$ & 1 & 9.09 & 10 & 90.90 & 0 & 0 \\
\hline & 58 & $120->1200$ & 15 & 25.86 & 34 & 58.62 & 9 & 15.51 \\
\hline
\end{tabular}

NT $=$ Number of total bands.

$\mathrm{NP}=$ Number of Polymorphic bands.

$\mathrm{NM}=$ Number of Monomorphic bands.

$\mathrm{NU}=$ Number of Unique Bands.

Polymorphic $=$ NP $/ \mathrm{NT} \times 100$

Monomorphic $=\mathrm{NM} / \mathrm{NT} \times 100$

\subsection{Data Analysis:}

Obtained data from gel screening by RAPD - PCR technique results were analyzed using the Numerical Taxonomy and Multivariate Analysis System NTSYS-pc statistical package version 2.1[17].

This data matrix was used to calculate the similarity within and among Amaranth species based on Jaccard's similarity coefficientsand genetic tree.The dendrogram displaying the genetic relationships among the genotypes was constructed by the Unweighted Pair Group Method with Arithmetic Mean (UPGMA) [18].

The detected polymorphic fragments data were analyzed. The amplification profile of all the studied species for the given primer were compared with each other, they scored as " 1 " for presence of band and " 0 " for the absence of the same band in the same size in other species. Only obvious clearly and reproducible amplified fragments were considered and calculated for genetic relationship analysis. The Genetic distances (G.D.) were estimated based on the data matrix obtained between pairs of the species according to [19] and according to the following formula:

G.D. $=1-\{2 \mathrm{Nab} /(\mathrm{Na}+\mathrm{Nb})\}$

Where $\mathrm{Na}=$ total number of fragments of species ' $\mathrm{a}$; $\mathrm{Nb}=$ total number of fragments species ' $\mathrm{b}$ ' and $\mathrm{Nab}=$ number of fragments shared by species 'a' and species 'b'.

\section{Results \& Discussion:}

The total number of RAPD amplified fragments that produced using the 6 primers was 195 bands, (Figure 1) these bands ranged from 25 using primer OP-S238 to 37 with the primer OP-S253. The total number of bands that frequented with consider to molecular weights were 58 over 34 frequent polymorphic bands means that above $58 \%$ of the bands were polymorphic (Table 2). It is worth mentioning that many unique bands appeared in the gel and for all the species studied, thus the total number of unique bands is $15(25.86 \%)$, while the total number of monomorphic bands is $9(15.51 \%)$, which is less than the polymorphic bands percentage and that reveal the high genetic polymorphism of this Family[20]. 


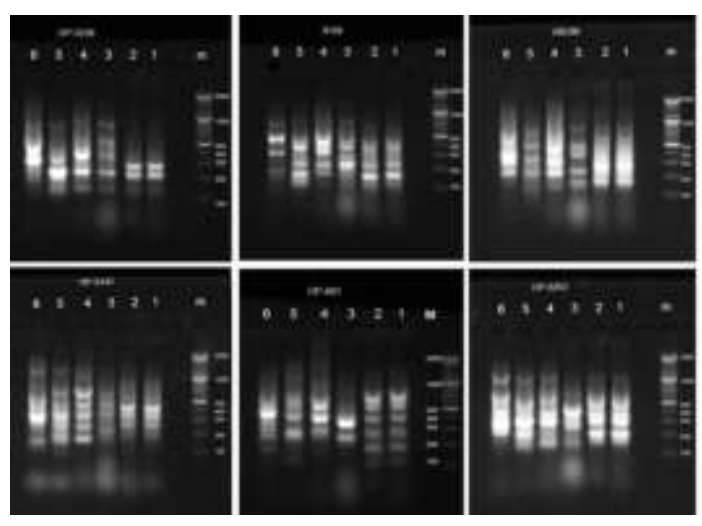

Fig. 1: Gel electrophoresis of DNA amplification bands for 6 studied species of Amaranthaceae family by using 6 different primers, m: molecular weight marker DNA Ladder (100-bp).

The studied species of the Amaranthaceae family showed high polymorphism due to the genetic differences among the four studied genera and from different tolerances as drought and salinity and Weather fluctuations in Iraq.

Representative polymorphisms that revealed by RAPD primers were presented in (Table 2), It is worth mentioning here that the dendrogram showed that the genetic relationships among the 6 Amaranth genotypes (Figure 2) and essentially divided into two main groups. The first one included Amaranthus retroflexus and A. spinosus, which separated at the similarity value of 0.54 , while the second group included the other Amaranthus species and contained two subgroups, the first one included A. albus, and the second one that appeared related correlation at similarity range of about 0.41 contained 2 species, Alternathera sessiles and Gmphrena globosa, while the second subgroup of the second group included Iresine herbstis only.

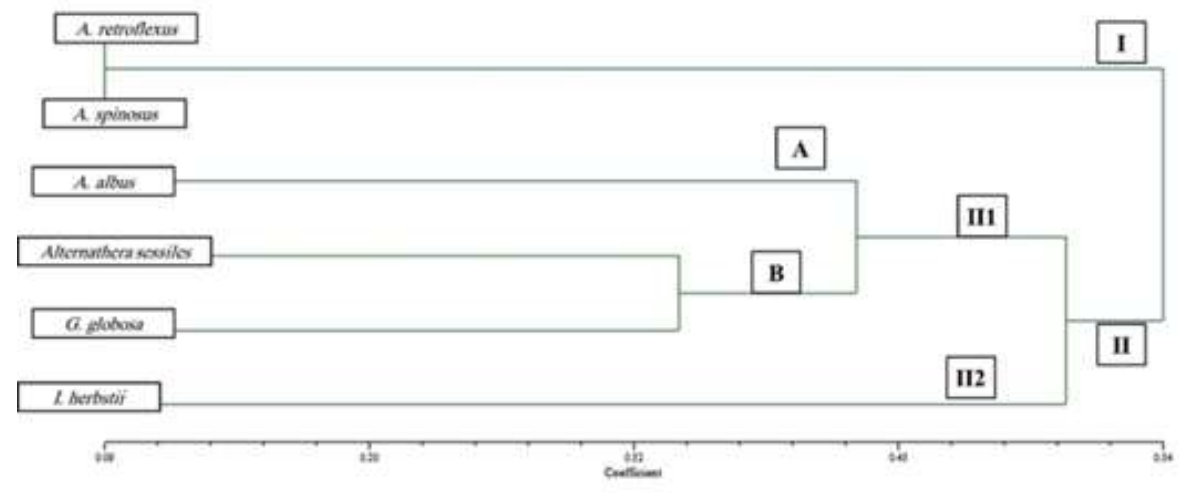

Fig. 2: Dendrogram Showing the Genetic Relationships Among Studied Species.

\subsection{Genetic Distances:}

The genetic distance value ranged from 0.334 (33\%) between Alternathera sessiles and Gmphrena globosa to highest 0.934 (93\%) between Amaranthus retroflexusas and A. spinosus as showed in (Table 3).

TABLE III: Values of Genetic Distances Among Amaranthus Species Calculated According to Nei \& Li's Formula (19).

\begin{tabular}{|c|c|c|c|c|c|c|}
\hline Amaranthus retroflexus & 1 & & & & & \\
\hline A. spinosus & 0.934 & 1 & & & & \\
\hline A. albus & 0.587 & 0.645 & 1 & & & \\
\hline Alternathera sessiles & 0.530 & 0.632 & 0.3578 & 1 & & \\
\hline Gomphrenaglobosa & 0.405 & 0.477 & 0.461 & 0.334 & 1 & \\
\hline Iresine herbstii & 0.516 & 0.510 & 0.611 & 0.387 & 0.493 & 1 \\
\hline
\end{tabular}


DNA amplification and species identification used to study the genetic diversity and the relationships among 6 Amaranthus species grown in Iraq which evaluated by RAPD-PCR method using 6 random primers obtained.

High percentage of polymorphic bands expressed by random primers in this study in comparison with the studies on the same plant, Popa etal. 2010 studied six Amaranth species from different geographic regions using RAPD molecular analysis showed relatively low intra- and inter-species polymorphism [21], however by using specific RAPD primers we can amplify some amplicons that, after further analysis, could be regarded as good molecular markers. [22].

In this study, high genetic polymorphism found agreed with the morphological and anatomical studies of some Iraqi Species of Amaranthaceae family [10].

Polymorphism between and within species may showed high level of polymorphism if plant sampling taken from far areas due to geographic effect to genetic traits [23].

\section{Conclusion}

The result indicate the high degree of correlation among 6 studied species according to RAPD-PCR technique and data analysis by the scientific methods used in the this study. These results gave an effective tool to understand the ralations among these species genetically.

\section{References}

[1] Akhani H., Trimborn P., Ziegle H. Photosynthetic pathways in Chenopodiaceae from Africa, Asia and Europe with their ecological, phytogeographical and taxonomical importance. Plant Systematic and Evolution, 1997, 206(1-4): $187-221$.

[2] Le Houerou, H.N., Salt-tolerant Plants for the Arid Regions of the Mediterranean Isoclimatic Zone. In: Towards the Rational Use of High Salinity Tolerant Plants, 1993, Vol. 1. pp. 403-422, Lieth, H. and Masoom, A., Eds., Kluwer Academic Publishers, Dordrecht.

[3] Adewale, A. and Olorunju, A. E. , Modulatory effects of fresh Amaranthus hybridus aqueous leaf extract on detoxify enzymes and micronuclei formation after expose to sodium arsenate. Pharmacognosy, Res. 2013, 5(4): 300-305 .

[4] Christenhusz, M. J. M.and Byng, J. W., The number of known plants species in the world and its annual increase. Phytotaxa, 2016, 261 (3): 201-217.

[5] $\mathrm{Xu}, \mathrm{F} .$. and Sun, M. Comparative analysis of phylogenetic relationships of grain amaranths and their wild relatives (Amaranthus; Amaranthaceae) using internal transcribed spacer, amplified fragment length polymorphism, and double-primer fluorescent intersimple sequence repeat markers. Mol. Phylogenet. Evol. 2001, 21(3): 372-387.

[6] Stussey, T.F. Plant Taxonomy: The Systematic of comparison data. 1990, Columbia University Press. New York.

[7] Akin-Idowu, P. E., Gbadegesin, M. A., Orkpeh, U., Ibitoye, D.O. and Odunola, O. A. ,Characterization of grain Amaranth (Amaranthus spp.) germplasm in southwest Nigeria using morphological, nutritional, and random amplified polymorphic DNA (RAPD) Analysis., Resources ,2016,5(1), 6: 1-15

[8] Williams, J.G.K., Kubelik, A.R., Livak, K.J., Rafalski, J.A. and Tingey, S.V. ,DNA polymorphisms amplified by arbitrary primers are useful as genetic markers. Nucleic Acids Res.,1990, 18(22): 6531-6535.

[9] Mondini, L., Noorani, A. and Pagnotta, M. A. Assessing plant genetic diversity by molecular tools. Diversity. ,2009,1(1): 19-35.

[10] Khalaf, F.K., (2016), Comparative anatomical study of taxa from the family Amaranthaceae in Iraq, MSc. Thesis, University of Baghdad.

[11] Sa'ad, N.S., Artanti, R. and Dewi, T., Phyto-remediation for rehabilitation of agricultural land contaminated by cadmium and copper. Phyto-remediation for rehabilitation,2011, 4(1):17-21.

[12] Mabry, T.J, Kagan J. and Rossler H. ,Polychemistry, 1965, Academic Press. New York. 
[13] Stafford, H.A., Anthocyanins and Betalains: Evolution of the Mutually Exclusive Pathways. Plant Sci. ,1994, 101(2): 91-98.

[14] Han, X.H., Gao Z.J. and Xiao X.G. Review Enzymes and Genes Involved in the Betalain Biosynthesis in Higher Plants. African J. Biotechnol, 2009, 8(24): 6735-6744.

[15] Doyle, J. J. and Doyle, J. L. Isolation of plant DNA from fresh tissue. FOCUS, 1990, 12(1):13-15.

[16] Liber, Z., Park, J. M., Kova, I. S., Eddie, W. M. and Schneeweiss, G. M. ,Phylogeny and biogeography of isophyllous species of Campanula (Campanulaceae) in the Mediterranean area. Syst. Bot. ,2006, 31(4): 862- 880.

[17] Roholf, F.J. ,NTSYS Pc, Numerical taxonomy and multivariate analysis system.Version 2.1.47 Roult 25A, Suit 2, Setauket, New York, 2004,11733-2870.

[18] Sneath, P.H.A. and Sokal, R.R. ,Numerical Taxonomy: The Principles and Practice of Numerical Classification. W.H. Freeman co .San Francisco, 1973, p:573.

[19] Nei, M. and Li, W.H. Mathematical model for studying genetic variation in terms of restriction Endonucleases Pro. Nat.Acad. Sci., USA.,1979 ,74, 5269-5273.Cited by Henry, R.J. 1997.

[20] Costea, M., Weaver, S. and Tardif, F. J. , The biology of Canadian weeds. 130. Amaranthus retroflexus L., A. powellii S. Watson and A. hybridus L. (update). Can. J. Plant Sci., 2004 , 84(2): 631-668.

[21] Popa, G., Cornea, C.P., Ciuca, M., Babeanu, N., Popa, O. and Marin, D., Studies on genetic diversity in Amaranthus species using the RAPD markers. Analele Universităţii din Oradea-Fascicula Biologie , 2010 , 17(2):280-285.

[22] Štefúnová, V., Bežo, M., Žiarovská, J., Ražná, K., Detection of the genetic variability of Amaranthus by RAPD and ISSR markers. Pak. J. Bot., 2015, 47(4): 1293-1301.

[23] Snezana D. M., Marija K., Danijela R., Milena S.and Lidija S. , Assessment of genetic relatedness of the two Amaranthus retroflexus populations by protein and random amplified polymorphic DNA (RAPD) markers, African J.Biotechnol., 2012 ,11(29):7331-7337. 